\title{
INTERVENTION EFFECT OF DANCE THERAPY BASED ON THE SATIR MODEL ON THE MENTAL HEALTH OF ADOLESCENTS DURING THE COVID-19 EPIDEMIC
}

\author{
Shuai Shao \\ Liaoning Normal University, Dalian, China
}

received: 3.5.2021;

revised: 15.7.2021;

accepted: 29.7.2021

\section{SUMMARY}

Background: To investigate the intervention effect of dance therapy based on the Satir Model on the mental health of adolescents with depression during the COVID-19 epidemic.

Subjects and methods: A total of 62 adolescents with depression were selected using Symptom Checklist 90 and randomly divided into two groups according to the matching of male and female participants; the experiment group had 32 members and the control group had 30 members. The experiment group received group psychological intervention and dance therapy based on the Satir Model, whereas the control group was not given any intervention.

Results: After the intervention, the scores of the experiment group in anxiety and depression are lower than those prior to intervention $(p<0.01)$ and of the control group $(p<0.01)$; the scores of the experiment group in life satisfaction, psychological resilience and their dimensions are higher than those prior to intervention $(p<0.01)$ and higher than those of the control group $(p<0.01)$.

Conclusions: The combination of group intervention and dance therapy based on the Satir Model is a feasible method to effectively alleviate adolescents' anxiety and depression, promote their life satisfaction and psychological resilience, and thus improve their mental health.

Key words: dance therapy - anxiety - depression - the Satir Model - psychological resilience - COVID-19

\section{INTRODUCTION}

With the continuous prevalence of the Corona Virus Disease 2019 (COVID-19) in 2020, many countries and regions have adopted a series of measures to prevent the spread of the disease, such as closing down populationintensive institutions and requiring the public to maintain social distance. In this context, all educational institutions at various levels have also been forced to cease their offline activities. Consequently, adolescents are faced with suspension of offline learning, lack of non-academic support previously provided by the school, and reduction in normal peer communication (Aslam \& Ahmed 2020, Ding \& Yao 2020, Joseph et al. 2020). The outbreak and continuous spread of the COVID-19 epidemic have altered the growth environment of children and adolescents, threatened their health, and greatly challenged their psychological development. Liu et al. (2021) found that psychological problems, such as fear, anxiety, depression, and somatization, have occurred frequently in ordinary children and special children during the epidemic. MuñozFernández \& Rodríguez-Meirinhos (2020) pointed out that since the outbreak of COVID-19, the incidence of emotional and behavioral problems in children and adolescents has been higher than ever. In an investigation conducted by Sheng et al. (2020), 85.7\% of the parents reported emotional changes in their children during the period of schooling suspension. The common symptoms are poor concentration, boredom, irritability, fidget, and tension. Wang et al. (2020) analyzed 396 Chinese adolescents aged 8-18 years old. He discovered that $22.0 \%$ of adolescents suffer from anxiety disorder during the epidemic, $4.1 \%$ higher than the level in the non-epidemic period. Another study revealed that some adolescents have more psychological problems and higher levels of post-traumatic stress disorders after the outbreak of COVID-19. Li et al. (2020) reported that the incidence of depression symptoms in adolescents is between $22.6 \%$ and $43.7 \%$ during the COVID-19 epidemic. Meanwhile, in two other studies, the incidence of anxiety symptoms in adolescents is approximately between $18.9 \%$ and $37.4 \%$, and the level of depression is similar to or even higher than Tang's estimation.

The Satir Model is a humanism-oriented psychotherapy model constructed by Virginia Satir, a family therapist in the United States (Seo \& Kim 2016). Characterized by focusing on change, highlighting the use of one's own resources, emphasizing experience, systematization, and positivity, this model aims to help individuals better understand themselves, enhance their self-worth, and promote their internal balance and harmony (Yldrm 2017). First, when faced with pressure, most individuals would prefer their familiar coping styles because they are afraid of change. However, this model holds that change is always possible, and people always have resources to deal with problems and changes. The problem itself is not a problem but how to deal with it. The focus of treatment should be on 
improving individuals' coping ability. Second, experiential training is applied to enhance individuals' inner awareness and increase their self-control and management ability. Finally, the treatment process is systematic to reach the predetermined positive objectives (Banmen 2002, Erker 2017). Some researchers have suggested that the combination of the Satir Model and group psychological intervention can achieve a satisfactory intervention effect (Wang \& Peng 2017) because their coordination forms a learning process in which experience, internal and external integrity, behavior exercise, and awareness and acceptance of internal feelings are present (Liu \& Li 2018). In recent years, group psychological intervention based on the Satir Model has been widely used because of its operability, controllability, short time, and fast effect; it has achieved a good intervention effect (Hu et al. 2020).

The intervention effect of the traditional psychological intervention mode, dominated by language communication, depends largely on the degree to which the individual would cooperate. When the individual is active in oral expression, the treatment is smooth and the effect is better. However, when the individual is unwilling to speak, the treatment process is slow and the effect is unsatisfactory. Dance therapy can make up for the deficiency of traditional psychotherapy dominated by language communication (Xie \& Wang 2018); it reaches the individual's inner world in the form of nonverbal information. Dance therapy is an expressive art therapy that uses dance or movement processes to promote emotional, physical, cognitive, and social integration in the individual (Strassel et al. 2011). A certain interaction exists between the body and the mind. When abnormality is observed in the body, the mind is affected, and vice versa. Any mental abnormality in an individual is disclosed in body movements. Whether it is a big or small movement, it displays the individual's subconscious information. As a new psychotherapy, dance therapy can help individuals release negative emotions and mobilize positive emotions. The therapist can also analyze and interpret dance movements, understand the individual's inner evolution, find out internal conflicts, identify the root cause of the problem, and achieve the objective of psychotherapy, thereby improving the individual's cognitive and psychological status. Dance therapy has been widely applied in clinical treatment, psychological intervention, improvement of physical functions, and other fields. The targets of dance therapy also range from children to the elderly in all age groups (Panagiotopoulou 2018, Filar-Mierzwa et al. 2017).

In conclusion, the Satir Model enables individuals to solve problems by using their own resources, focuses on improving individuals' coping ability, and is easily accepted by adolescents. Dance therapy is suitable for adolescents because it allows individuals to express themselves through body movements, and group intervention is effective to improve their mental health. Therefore, the Satir Model and dance therapy were combined in the group psychological intervention to intervene in the mental health of adolescents with depression during COVID-19. The effects of this comprehensive group psychological counseling in improving anxiety and depression, life satisfaction, and psychological resilience of adolescents were investigated to identify effective intervention methods to solve the psychological problems of adolescents and provide reference for promoting the mental health of adolescents during COVID-19.

\section{SUBJECTS AND METHODS}

\section{Participants}

During October-December 2020, the method of convenience sampling was adopted to randomly select four communities in Zhongshan District and Xigang District of Dalian City, Liaoning Province and recruit adolescent volunteers. After the publicity and explanation by the research team, 1870 adolescent volunteers agreed to participate in the study. The 1870 volunteers were screened with Symptom Checklist 90 (SCL-90), and 94 adolescents were detected to have depression symptoms, according to the criterion of depression factor greater than 3 . The detected adolescents were included in the group after a brief interview in line with the principle of voluntary participation. A total of 62 adolescents, who finally completed all the experiment contents, were randomly divided into two groups according to the matching between male and female participants. The experiment group has 32 participants ( 15 boys and 17 girls), aged $15.67 \pm 1.01$ years old, and the control group has 30 participants ( 15 boys and 15 girls), aged $15.98 \pm 0.11$ years old. The inclusion criteria are as follows: 1 - those who are healthy and without physical diseases; 2 - those who volunteer to participate in group psychological counseling; 3 - those who are willing to complete the questionnaire survey carefully. The exclusion criteria are as follows: 1 those who have serious psychological problems or mental diseases and are accepting drug treatment; 2 those who are receiving psychological consultation or continuous systematic psychological counseling; 3 those who are unwilling to complete the questionnaire survey; 4 - those with serious physical diseases. All the participants in this study understood the purpose, methods, and precautions of the study. All the scales were filled in anonymously by the participants and were collected on the spot.

\section{Methods}

The measurement of the experiment group and the control group before and after the comprehensive group psychological intervention was used for the experiment design. All the participants were measured using SCL90 to identify the benchmark level prior to the group psychological intervention. Then, the experiment group was intervened according to the group psychological intervention scheme formulated by the research team. 
The comprehensive group psychological counseling conducted in the experiment group refers to the combination of group psychological intervention and dance therapy based on the Satir Model. The specific intervention procedure for the experiment group is as follows: group psychological intervention of the Satir Model is the first part of the comprehensive group counseling scheme. This intervention was conducted for seven weeks, once a week, approximately 1 hour each time. The design of the group psychological intervention scheme was developed based on iceberg theory in the Satir Model (Li 2019), focused on love and relationship, held the four objectives of the Satir Model as the purpose, and combined the five elements of the Satir Model to guide students to engage in learning, understanding, perception, experience, change, and growth. Meanwhile, with the emphasis on the common psychological confusion and psychological problems among adolescents, the group psychological intervention scheme was designed to improve adolescents' ability to obtain deeper understanding of themselves and others, improve their self-confidence and emotional management ability, and promote their mental health level. The group psychological intervention scheme includes eight themes, namely, using the iceberg theory ( $\mathrm{Li} 2019$ ) to understand themselves, using the iceberg theory to know others in groups, experiencing and learning their own and others' psychological state, experiencing the relation between interpersonal relationship and mental health in groups, exploring their internal advantages and improving personal energy, cultivating personal happiness, understanding the generation of emotions, and experiencing ways to regulate emotions.

Dance therapy is the second part of the comprehensive group counseling scheme. The participants in the experiment group received group dance psychological intervention. The group dance psychological course contained eight theme tasks, with a task completed each time. The intervention was carried out for eight weeks, once a week, 2 hours each time. The dance leader is a dance professional teacher in a university and focuses on practical social use on the premise of the explanation and training of the key movements. Dance therapy included the following four links each time: 1) warm-up activities: learners were guided to know each movement and experience free expression through movements; 2) clarification of the task: learners were encouraged to use body language in a positive manner and present their own thoughts freely; 3) key points: appropriate teacher assistance was provided to help learners express their subjective experience, share personal life stories, identify the problem, and seek the most appropriate approach to vent and solve the problem; 4) relaxing movement and ending: a positive, warm, and sincere atmosphere of group activities was established in the entire intervention process, and the activities were ended with positive wordings, such as love for life, to maintain the vitality of the group.

The students in the control group did not participate in any group psychological counseling activities or psychological counseling during the experiment period. They complete the comparative measurement before and after intervention with the experiment group in terms of life satisfaction, anxiety/depression, and psychological resilience to explore the effect of comprehensive group psychological intervention in improving the mental health level of adolescents.

\section{Measuring Tools}

- Symptom Checklist 90 (SCL-90) (Derogatis et al. 1973, Liu \& Zhang 2004): Symptom Checklist 90 (SCL-90) was used in this study. A common scale that contains 90 items is used to measure mental health level. The scale covers 10 factors, including somatization, compulsion, interpersonal sensitivity, depression, anxiety, hostility, terror, paranoia, psychosis, and others (diet and sleep status). The participant gives $1-5$ points according to the actual situation when filling in the scale. The factor higher than 3 points can be used as the criterion for judging mental disorders. The reliability coefficient of the scale is 0.96 , suggesting that it has good reliability and validity.

- Life Satisfaction Scale (Xiong \& Xu 2009): Life Satisfaction Scale compiled by Pavot and Diener (2009) and revised by Xiong \& Xu (2006) was used for measurement. It has five items that are rated from 1 to 7 points. The Cronbach $\alpha$ coefficient of the scale is 0.81 .

- Anxiety and Depression Scale (Su et al. 2006): The Anxiety and Depression Subscale of Achenbach Youth Self-Report compiled by Achenbach and revised by Liu Xianchen was used for measurement. It contains 16 items that are rated from 0 (never) to 4 points (often). The Cronbach $\alpha$ coefficient of the scale is 0.83 .

- Measurement of psychological resilience (Hu \& Gan 2008): Healthy Kids Resilience Assessment compiled by $\mathrm{Hu} \&$ Gan (2008) was used for measurement. The scale contains 27 items in five dimensions, including goal concentration, positive cognition, emotional control, family support, and interpersonal assistance. A higher score suggests a higher psychological resilience level. The Cronbach $\alpha$ coefficient of the scale is 0.81 .

\section{Statistical Analysis}

All the data in this study were processed using SPSS 17.0 statistical software. The comparison between groups was conducted using independent sample t test, and the comparison within the group was conducted using paired sample $\mathrm{t}$ test. The difference is statistically significant at $p>0.05$. 


\section{RESULTS}

\section{Comparison of the intervention effect on life satisfaction between two groups before and after intervention}

The scores of the experiment group and the control group in life satisfaction before and after the intervention were compared using independent sample $t$ test and paired sample $t$ test, respectively. The results are shown in the table above. The table shows no significant difference in life satisfaction between the experiment group and the control group prior to intervention. After the intervention, the life satisfaction level of the experiment group is significantly higher than that of the control group and that prior to intervention. At the same time, the life satisfaction level of the control group after the intervention is significantly higher than that prior to the intervention (Table 1).

\section{Comparison of the intervention effect on depression/anxiety between the experiment group and the control group before and after intervention}

The scores of the experiment group and the control group in depression/anxiety before and after the intervention were compared using independent sample $t$ test and paired sample $t$ test, respectively. The results are shown in Table 2. Table 2 shows no significant difference in depression/anxiety between the experiment group and the control group before the intervention. After the intervention, the life depression/anxiety level of the experiment group is significantly lower than that of the control group and significantly lower than that prior to the intervention. No significant change is found in the depression level of the control group before and after the intervention.

Table 1. Comparison of life satisfaction between two groups before and after intervention $(\mathrm{M} \pm \mathrm{SD})$

\begin{tabular}{lcccc}
\hline & Experimental group $(\mathrm{n}=32)$ & Control group $(\mathrm{n}=30)$ & $\mathrm{t}$ & $\mathrm{p}$ \\
\hline Before intervention & $2.01 \pm 0.36$ & $1.97 \pm 0.42$ & 0.46 & 0.65 \\
After intervention & $5.46 \pm 0.45$ & $2.93 \pm 0.38$ & 23.74 & 0.00 \\
$\mathrm{t}$ & -33.31 & -8.61 & & \\
$\mathrm{p}$ & 0.00 & 0.00 & \\
\hline
\end{tabular}

Table 2. Comparison of depression/anxiety between two groups before and after intervention $(\mathrm{M} \pm \mathrm{SD})$

\begin{tabular}{lcccc}
\hline & Experimental group $(\mathrm{n}=32)$ & Control group $(\mathrm{n}=30)$ & $\mathrm{t}$ & $\mathrm{p}$ \\
\hline Before intervention & $2.09 \pm 0.21$ & $3.00 \pm 0.20$ & -0.52 & 0.61 \\
After intervention & $1.55 \pm 0.33$ & $2.99 \pm 0.20$ & -20.75 & 0.00 \\
$\mathrm{t}$ & 20.62 & 0.12 & & \\
$\mathrm{p}$ & 0.00 & 0.90 & \\
\hline
\end{tabular}

Table 3. Comparison of psychological resilience between two groups before and after intervention $(\mathrm{M} \pm \mathrm{SD})$

\begin{tabular}{|c|c|c|c|c|c|}
\hline & & Experimental group $(n=32)$ & Control group $(n=30)$ & $\mathrm{t}$ & $\mathrm{p}$ \\
\hline $\begin{array}{l}\text { Psychological } \\
\text { resilience }\end{array}$ & $\begin{array}{l}\text { Before intervention } \\
\text { After intervention } \\
\mathrm{t} \\
\mathrm{p}\end{array}$ & $\begin{array}{c}1.98 \pm 0.15 \\
4.02 \pm 0.15 \\
-55.72 \\
0.00\end{array}$ & $\begin{array}{c}1.98 \pm 0.17 \\
2.48 \pm 0.27 \\
-8.51 \\
0.00\end{array}$ & $\begin{array}{l}-0.16 \\
27.52\end{array}$ & $\begin{array}{l}0.88 \\
0.00\end{array}$ \\
\hline $\begin{array}{l}\text { Goal } \\
\text { concentration }\end{array}$ & $\begin{array}{l}\text { Before intervention } \\
\text { After intervention } \\
t \\
p\end{array}$ & $\begin{array}{c}1.92 \pm 0.30 \\
3.96 \pm 0.37 \\
-23.59 \\
0.00\end{array}$ & $\begin{array}{l}2.01 \pm 0.39 \\
2.43 \pm 0.53 \\
\quad-3.75\end{array}$ & $\begin{array}{l}-1.07 \\
13.26\end{array}$ & $\begin{array}{l}0.28 \\
0.00\end{array}$ \\
\hline Family support & $\begin{array}{l}\text { Before intervention } \\
\text { After intervention } \\
t \\
p\end{array}$ & $\begin{array}{c}1.94 \pm 0.39 \\
3.99 \pm 0.37 \\
-223.29 \\
0.00\end{array}$ & $\begin{array}{l}2.09 \pm 0.38 \\
2.40 \pm 0.48 \\
\quad-2.95 \\
0.00\end{array}$ & $\begin{array}{l}-1.47 \\
14.65\end{array}$ & $\begin{array}{l}0.15 \\
0.00\end{array}$ \\
\hline $\begin{array}{l}\text { Positive } \\
\text { cognition }\end{array}$ & $\begin{array}{l}\text { Before intervention } \\
\text { After intervention } \\
t \\
p\end{array}$ & $\begin{array}{l}1.98 \pm 0.35 \\
4.07 \pm 0.37 \\
-26.85 \\
0.00\end{array}$ & $\begin{array}{l}2.04 \pm 0.41 \\
2.42 \pm 0.48 \\
\quad-3.73 \\
0.00\end{array}$ & $\begin{array}{l}-0.54 \\
16.18\end{array}$ & $\begin{array}{l}0.42 \\
0.00\end{array}$ \\
\hline $\begin{array}{l}\text { Emotional } \\
\text { control }\end{array}$ & $\begin{array}{l}\text { Before intervention } \\
\text { After intervention } \\
t \\
p\end{array}$ & $\begin{array}{l}1.91 \pm 0.35 \\
4.01 \pm 0.37 \\
-22.33 \\
0.00\end{array}$ & $\begin{array}{l}1.98 \pm 0.41 \\
2.49 \pm 0.48 \\
\quad-3.30 \\
0.00\end{array}$ & $\begin{array}{l}-0.79 \\
11.92\end{array}$ & $\begin{array}{l}0.21 \\
0.00\end{array}$ \\
\hline $\begin{array}{l}\text { Interpersonal } \\
\text { assistance }\end{array}$ & $\begin{array}{l}\text { Before intervention } \\
\text { After intervention } \\
\mathrm{t} \\
\mathrm{p}\end{array}$ & $\begin{array}{l}2.11 \pm 0.33 \\
4.07 \pm 0.31 \\
-22.61 \\
0.00\end{array}$ & $\begin{array}{l}1.84 \pm 0.31 \\
2.69 \pm 0.38 \\
-10.17 \\
0.00\end{array}$ & $\begin{array}{r}3.40 \\
15.57\end{array}$ & $\begin{array}{l}0.03 \\
0.00\end{array}$ \\
\hline
\end{tabular}




\section{Comparison of the intervention effect on psychological resilience between the experiment group and the control group before and after intervention}

The scores of the experiment group and the control group in psychological resilience and its dimensions before and after the intervention were compared using independent sample $\mathrm{t}$ test and paired sample $\mathrm{t}$ test, respectively. The results are shown in Table 3. Table 3 shows no significant difference in psychological resilience and its dimensions (except interpersonal assistance) between the experiment group and the control group prior to the intervention. After the intervention, the level of the experiment group in psychological resilience and its dimensions is significantly higher than those of the control group and significantly higher than those prior to the intervention. The psychological resilience level of the control group after the intervention is significantly higher than that prior to the intervention.

\section{DISCUSSION}

The results of this study show that after the intervention, the life satisfaction scores of the experiment group and the control group increase, but the score of the experiment group is significantly higher than that of the control group. This finding suggests that the combination of group psychological intervention and dance therapy based on the Satir Model can effectively improve the life satisfaction of adolescents.

The possible reasons why comprehensive group psychological counseling can improve the life satisfaction level of adolescents are as follows. First, most noticeably, the Satir Model can improve the selfesteem level of individuals (Jin \& Ma 2020). Meanwhile, group activities provide adolescents with sufficient emotional support and social support. Social support and self-esteem positively affect the promotion of the life satisfaction of adolescents ( $\mathrm{Li} \&$ Bian 2016, Wang \& Mu 2016). Second, listening, affirmation, and appreciation used in group psychological intervention based on the Satir Model can improve the core selfevaluation of adolescents; however, adolescents with higher core self-evaluation experience more positive emotions and have higher life satisfaction (Tan et al. 2016). Moreover, communication posture, meditation, experience sharing, and other links in group psychological intervention based on the Satir Model enable group members to realize that they have abundant available resources and help them integrate and optimize internal and external resources. After realizing that they can use existing resources to cope with the existing problem and adapt to the current environment, members have accurate cognition, positive attitudes, stronger ability, and more confidence in coping with the problem; therefore, they obtain a higher level of subjective well-being and life satisfaction. In addition, during dance therapy, adolescents can release negative emotions and experience positive emotions. Evidently, positive emotions encourage individuals to be more open, try new problem-solving strategies, seek more possibilities, and more actively construct lasting social and psychological resources for problem solving and personal development (Zhao et al. 2021). These advantages are conducive to the improvement of life satisfaction among adolescents.

The results of this study show that after the intervention, the decrease in anxiety/depression is significantly higher in the experiment group than in the control group. This finding suggests that the combination of group psychological intervention and dance therapy based on the Satir Model can effectively alleviate the anxiety and depression of adolescents. It also reflects that, different from life satisfaction, alleviating adolescents' anxiety and depression symptoms without intervention is difficult. Therefore, taking certain intervention measures during COVID-19 is necessary. The following mechanism explains why this intervention can relieve the anxiety and depression of adolescents: group psychological intervention based on the Satir Model assists adolescents to perceive their own anxiety and depression, identify the need and problem behind their emotions, know their own resources and abilities to solve the problem, and integrate their internal resources and interpersonal interaction to catalyze changes. First, adolescents engage in more interpersonal interactions during group activities. In the interaction process with other team members, adolescents receive attention, respect, encouragement, and appreciation from others, find their own uniqueness and advantages, experience self-worth and self-efficacy while helping others, gain more self-recognition, and obtain higher self-evaluation, self-acceptance, and self-esteem levels. These factors are helpful for alleviating anxiety and depression in an individual (Ander et al. 2017). Second, through communicating with and receiving feedback from other team members, adolescents are more likely to view themselves from different perspectives, fully understand themselves, and avoid giving themselves negative evaluation, thereby reducing their negative emotions. Finally, adolescents with depression suffer from the difficulty in expressing and regulating negative emotions. Dance therapy provide adolescents another means of expression. Their deep inner world, which is difficult to reach, is externalized and displayed through dance movements. In this process, negative emotions, such as anxiety and depression, can be released, and psychological pressure is relieved. In addition, dance therapy engages adolescents in self-perception and selfreflection and helps them clearly understand their own plight, enabling them to adopt targeted solutions.

The results of this study show that the combination of group psychological intervention and dance therapy based on the Satir Model can effectively increase the psychological resilience of adolescents, mainly manifested in the improvement in goal concentration, family support, positive cognition, emotional control, and inter- 
personal assistance. The following mechanism may explain why comprehensive group psychological counseling can increase the psychological resilience of adolescents. First, the group psychological intervention based on the Satir Model enables individuals to integrate support from family members, friends, and society, and the social support perceived by adolescents effectively improves their psychological resilience level (Graber et al. 2016). Second, during cooperation and communication with team members, adolescents have more self-awareness, obtain new ideas and new insights from others, eliminate their original thinking mode, seek more new approaches other than their original problemsolving methods, abandon the negative coping style, and form a new positive behavior mode. After adopting the positive coping style, adolescents focus more on solving problems, and their ability to deal with problems is improved constantly. Psychological resilience is exactly the ability of individuals to recover from negative experiences and adapt to the changeable external environment (Dennison et al. 2016). Therefore, the psychological resilience of adolescents is improved at the same time. Furthermore, dance therapy can mobilize the positive emotions of adolescents, make them more focused and open, form positive cognition, encourage them to learn to regulate emotions, improve their selfregulation and self-healing ability, and enable them to perform better in adaption and problem-solving when facing adversities in life. Their psychological resilience is also improved in this process. The improvement of psychological resilience can further contribute to the decrease in negative emotions, including anxiety and depression, increase in subjective well-being and life satisfaction (Eryilmaz 2011, Sotardi et al. 2020, Orúzar et al. 2019), and enhancement of mental health.

\section{CONCLUSION}

A comprehensive psychological intervention method, namely, the combination of group psychological intervention and dance therapy based on the Satir Model, was used for the first time to intervene in the mental health of adolescents with depression during COVID19. The results showed that this comprehensive group psychological counseling can effectively improve the mental health level of adolescents, alleviate their anxiety and depression, increase their life satisfaction, and promote their psychological resilience level. Therefore, this comprehensive psychological intervention can be applied and promoted in the mental health education among adolescents. It can also be used as a reference for the design of group intervention schemes to improve the mental health level of adolescents during COVID- 19.

\section{Acknowledgements: None.}

\section{Conflict of interest: None to declare.}

\section{References}

1. Ander M, Wikman A, Ljótsson B, Grönqvist H, Ljungman $G$, Woodford J, et al: Guided internet-administered selfhelp to reduce symptoms of anxiety and depression among adolescents and young adults diagnosed with cancer during adolescence (U-CARE: YoungCan): a study protocol for a feasibility trial. BMJ Open 2017; 7:e013906

2. Aslam $N \&$ Ahmed A: Prospective impact of COVID-19 on adolescents: guidelines for interventions. Psychiatr Danub 2020; 32:603-604

3. Banmen J: The Satir Model: Yesterday and Today. Contemporary Family Therapy 2020; 24:7-22

4. Dennison MJ, Sheridan MA, Busso DS, Jenness JL, Peverill M, Rosen ML, et al: Neurobehavioral markers of resilience to depression amongst adolescent exposed to child abuse. Journal of Abnormal Psychology 2016; 125:1201-1212

5. Derogatis LR, Lipman RS, Covi L: SCL-90: an outpatient psychiatric rating scale--preliminary report. Psychopharmacol Bull 1973; 9:13-28

6. Ding $X$, \& Yao J: Peer Education Intervention on Adolescents' Anxiety, Depression, and Sleep Disorder during the COVID-19 Pandemic. Psychiatr Danub 2020; 32:527-535

7. Erker J: A Summary of a Qualitative Study of Satir Family Therapy: Theoretical and Practical Developments over the Past 30 Years. Satir International Journal 2017; 2:76-81

8. Eryilmaz A: Satisfaction of Needs and Determining of Life Goals: A Model of Subjective Well-Being for Adolescents in High School. Kuram Ve Uygulamada Egitim Bilimleri 2011; 11:1757-1764

9. Filar-Mierzwa K, Marchewka A, Bac A, Kulis A, Dabrowski Z, Telegtów A, et al: Effects of dance therapy on the selected hematological and rheological indicators in older women. Clinical Hemorheology and Microcirculation 2017; 66:157-165

10. Graber R, Turner R, \& Madill A: Best friends and better coping: Facilitating psychological resilience through boys' and girls' closest friendships. British Journal of Psychology 2016; 107:338-358

11. Hu CH, Wang Q, Zhong D, Sun ML, \& Jiang D: The effect of group psychological intervention of Satya model on the interpersonal relationship of college students. China Journal of Health Psychology 2020; 28:767-771

12. Hu YQ, Gan YQ: Development and Psychometric Validity of the Resilience Scale for Chinese Adolescents. Acta Psychologica Sinic 2008; 40:902-912

13. Jin HX, \& Ma YR: Satya family therapy model Intervention effect on sub-health learning state of College Students Research on the mechanism of action. Journal of Campus Life \& Mental Health 2020; 18:88-91.

14. Joseph SJ, Bhandari SS, Ranjitkar S, Dutta S: School Closures and Mental Health Concerns for Children and Adolescents during the COVID-19 Pandemic. Psychiatr Danub 2020; 32:309-310

15. Li BL, \& Bian YF: Junior Middle School Students'Life Satisfaction and Effect of Social Support and Self-esteem: 3 Years Follow up. Chinese Journal of Clinical Psychology 2016; 24:900-904

16. Li JF: Practical exploration of case supervision based on Satya's internal Iceberg Theory. Mental Health Education in Primary and Secondary School 2019; 393:53-55 
17. Li SW, Wang Y, Yang YY, Lei XM, Yang YF: Investigation on the influencing factors for anxiety related emotional disorders of children and adolescents with home quarantine during the prevalence of coronavirus disease 2019. Chinese Journal of Child Health Care 2020; 28:407-410

18. Liu H, Zhang JX: Norm of Symptom Checklist (SCL-90) in Chinese Middle School Students. Chin Ment Health J 2004; 18:88-90

19. Liu L \& Li L: A case study on effects of Satir Model group counseling in reducing roommate conflicts among high school students. Chinese Mental Health Journal 2018; 32:215-219

20. Liu X, Jiang J, \& Zhang Y: Effects of Logotherapy-Based Mindfulness Intervention on In-ternet Addiction among Adolescents during the COVID-19 Pan-demic. Iranian Journal of Public Health 2021; 50:789-797

21. Muñoz-Fernández $N \&$ Rodríguez-Meirinhos A: Adolescents' Concerns, Routines, Peer Activities, Frustration, and Optimism in the Time of COVID-19 Confinement in Spain. Journal of Clinical Medicine 2021; 10:798

22. Orúzar H, Miranda R, Oriol X, Montserrat C: Self-control and subjective-wellbeing of adolescents in residential care: The moderator role of experienced happiness and daily-life activities with caregivers. Children and Youth Services Review 2019; 98:125-131

23. Panagiotopoulou E: Dance therapy and the public school: The development of social and emotional skills of high school students in Greece. The Arts in Psychotherapy 2018; 59:25-33

24. Pavot $W$ \& Diener E: Review of the satisfaction with life scale. In Assessing well-being, 101-117. Springer, Dordrecht, 2009

25. Seo SH \& Kim SJ: The Effects of a Parental Education Program based on Satir Transformational Systemic Therapy Model for Preschoolers' Mothers. Journal of Korean Academy of Psychiatric and Mental Health Nursing 2016; 24:330-330

26. Shen XS, Li X, Yan JW, Liu S, Hu SW, Guo PF, et al: Anxiety of primary and middle school students in Anhui province during the COVID-19 epidemic. Chinese Mental Health Journal 2020; 34:715-719
27. Sotardi VA, Watson $P$, Swit $C$, Roy D, Bajaj M: Adolescent Stress, Help-Seeking Intentions, Subjective Achievement, and Life Satisfaction in New Zealand: Tests of Mediation, Moderated Mediation and Moderation. Stress and Health 2020; In Press

28. Strassel JK, Cherkin DC, Steuten L, Sherman KJ \& Vrijhoef HJ: A systematic review of the evidence for the effectiveness of dance therapy. Altern Ther Health Med 2011; 17:50-59

29. Su LY, Gao XP, Jin Y, Liu J, Lou XR \& Wen H: Comorbidity of Anxiety and Depression in a Primary School Sample. Chinese Mental Health Journal 2006; 20:1-4

30. Tan J, Yang W, Ma H \& Yu Y: Adolescents' Core SelfEvaluations as Mediators of the Effect of Mindfulness on Life Satisfaction. Social Behavior and Personality: An International Journal 2016; 44:1115-1122

31. Wang EN, Peng X: Intervention Effect of Group Counseling on Meaning of Life: A Therapy Based on Sandplay and Satir Model. Chinese Journal of Clinical Psychology 2017; 25:315-318

32. Wang H, Li X, Dun Y, Liu YX, Li JH: Psychological care in children and adolescents during the COVID-19 epidemic. Chinese Mental Health Journa 2020; 34:269270

33. Wang XK, Li LZ \& Mu SK: The Effect of Social Support on Adolescents' Life Satisfaction: A Moderated Mediating Model. Journal of Minnan Normal University (Natural Science) 2016; 29:107-113

34. Xie $H \&$ Wang S: Effects of Dance Movement Therapy on Self-acceptance and Self-efficacy in College Students. Chinese Journal of Clinical Psychology 2017; 25:584-587

35. Xiong $C Q \& X u$ YL: Reliability and Validity of the Stisfaction with Life Scale for Chinese Demos. China Journal of Health Psycholog 2009; 17:948-949

36. Yldrm N: Virginia Satir's Family Education and Therapy Model. International Journal of Social Science Studies 2017; 5:72-79

37. Zhao Y, Wang Y, Qin $C$ \& Song H: The influence of positive emotion and negative emotion on creativity performance. Journal of Aba Teachers University 2021; $38: 121-128$

Correspondence:

Shuai Shao, MD

Liaoning Normal University

850\# Huanghe Road, Shahekou District, Dalian City, Liaoning Province, China

E-mail: shao2020828@163.com 